\title{
Assessing Farmer's Perception Towards Improved Quncho Teff Variety in Gindeberet District, West Showa Zone, Oromia Region Ethiopia
}

\author{
Dawit Milkias ${ }^{1}$,, Gemechu Beri \\ ${ }^{1}$ Department of Agricultural Economics, Ambo Agricultural Research Center, Ambo, Ethiopia \\ ${ }^{2}$ Planning, Monitoring and Evaluation Directorate, Ethiopian Institute of Agricultural Research, Addis Ababa, Ethiopia
}

Email address:

mkdave04@gmail.com (D. Milkias)

${ }^{*}$ Corresponding author

To cite this article:

Dawit Milkias, Gemechu Beri. Assessing Farmer's Perception Towards Improved Quncho Teff Variety in Gindeberet District, West Showa Zone, Oromia Region Ethiopia. Journal of Plant Sciences. Vol. 8, No. 5, 2020, pp. 106-111. doi: 10.11648/j.jps.20200805.11

Received: August 4, 2020; Accepted: August 17, 2020; Published: August 31, 2020

\begin{abstract}
Tef is among the major cereal crops in the Horn of Africa particularly in Ethiopia where it is number one in terms of land allocated to its cultivation. This crop is the major staple food crop to most of the Ethiopian people living in the highlands which comprise more than $65 \%$ of the population. This study was aimed at analyzing farmers' perception towards improved Quncho teff varieties and constraints faced in producing improved teff variety in Gindeberet district. A descriptive survey design was adopted in which 150 respondents were randomly selected from six Peasant association of the district to collect the required data. The study result revealed that depending on the items developed for this study among the given agreements perception on high yield potential of the variety, increase production and yield, availability of the technology on production and agro-ecological suitability of the variety had showed relatively best performance of the varieties, whereas availability of the improved seed at the right time with its quality and disease resistance of the crop indicates relatively poorest agreement compared to all other characteristics of level of agreements considered. The overall finding revealed that, the government and other stakeholders should invest in farmer training since it enables farmers to understand well technologies and perceive their benefits increasing their probability to adopt agricultural technologies and provide adequate extension services and solve un availability of improved seed at the right time, high prices of inputs particularly improved seeds, pesticides and fertilizers in the district.
\end{abstract}

Keywords: Quncho Teff, Gindeberet, Inputs, Best Performance

\section{Introduction}

More than $85 \%$ of the Ethiopian population, which resides in the rural area, is engaged in agricultural production as a major means of livelihood [34]. The agricultural production system is mainly rain fed and traditional, which is characterized by low input of improved seeds, fertilizer, pesticides and other technologies [19]. Moreover, the ever increasing population pressure led to decline in land holding per household that eventually resulted in low level of production to meet even the consumption requirement of the households [6]. Agricultural productivity in general and crop production in particular has been given heavy emphasis over the last two decades in almost all development policies and strategies of the country.

Crops are the major agricultural commodities on which Ethiopians depend for their daily food [24]. Teff is among the major cereal crops in the Horn of Africa particularly in Ethiopia where it is number one in terms of acreage allocated to its cultivation. It is grown by about 6.5 million smallholder farmers on over three million hectares of land, which is equivalent to $30 \%$ of the total area allocated to cereals [8]. Teff is likely to remain a favorite crop of the Ethiopian population and the crop is also gaining popularity in the western world as a source of food; because of its health advantage for the people having celiac disease [10]. It is also used as a source of income for the farm family in addition to its importance as human food and animal feed [14]. In terms 
of its nutritional values, teff stands at least at a comparable level with those of other major cereals like wheat, maize, barley and sorghum that have globally significant; while it is rich in iron content as compared to other cereals [5]. Teff is the major staple food crop to most of the Ethiopian people living in the highlands which comprise more than $65 \%$ of the population. However, the national average yield of teff is very low and 1.4 ton per hectare and the development of high yielding cultivars would be very beneficial [9].

The wide-scale cultivation of teff is related to its tolerance to diverse environmental constraints, which include both excess and scarce soil moisture. In addition to being nutritious, tef grains are free of gluten [26], a causal agent for celiac disease; and hence teff is becoming globally popular as a life-style crop [23]. Despite these agronomical and nutritional benefits of tef, both the total production and productivity of tef is relatively low. The main reasons for inferior yield of tef are suboptimal genetic gain, low access to seeds of improved varieties, poor agronomic practices and lodging $[18,20]$. Although 42 improved tef varieties have been released by the National Research System in Ethiopia [21], their adoption by farmers is low [18]. The central issue of applying the latest agricultural technology and/or innovation lies not only on the improvement of farm performances but also on the impact of technology on social and economic conditions of rural households, and on the promotion of land and labor productivity in agricultural sector.

Hence, the need for improved crop varieties that are high yielding and with the capacity to survive in such a degraded and risk prone environment is important [27]. Therefore, there is still a question of yield stagnation due to the low yield potential on the existing teff varieties [28].

To overcome this problem, Ethiopian Institute of Agricultural Research developed and released different improved teff varieties to solve the production problem of the farming community. The author [31] indicated that, Quncho teff variety was developed by Debre Zeit Agricultural Research Center (DZARC) from two parent materials Dukem (DZ-01-974) and Magna (DZ01-196) through targeted cross between the two varieties with the objective of selecting recombinants developed as a single-seed descent derived inbred line after series of multi environment yield tests in various major teff growing regions of the country and officially released in 2006 [22]. The variety has more than doubled teff productivity: up to $137 \%$ from 1.6 tons per hectare to 3.8 tons per hectare through following management practices is important in increasing the yield [33].

In the study area improved Quncho teff technologies are being promoted by research center and the district office of agriculture. Nevertheless it is not investigated the farmer's perceptions on the variety as well as factors affecting adoption of it. Therefore, this study has fundamentally focusing on the perceptions of farmers towards the technologies and constraints faced in producing improved teff variety may provide the answers since they deal with the technologies and they probably perceive technologies differently than researchers and extension agents. The technologies promoted include improved varieties, recommended fertilizer rates and types, improved agronomic and weed control practices. Having implemented many interventions, this study was mainly done to know the outline of farmer respondents and to examine their perception towards the varieties, in the district.

\section{Review of Literature}

From the cereal crops teff accounts for about a quarter of total cereal crop production in Ethiopia. According to [33] teff is currently the most expensive grain in Ethiopia because it requires labor intensive harvesting and processing techniques, while producing the lowest yield per hectare of all cereal crops. Economic indicators unveil that teff is the most dominant cereal crop in Ethiopian agriculture. For instance, in 2010 cropping season, it was estimated that a total of 3.2 million tons of teff has been produced on 2.59 million hectare of land [7]. This is equivalent to 20.50 and $28 \%$ of the total cereal crop production and acreage in the country respectively. This makes teff the leading crop among cereals and even among other annual crops.

Teff is Ethiopia's most important cereal crop, but the national average yield level is low. One of the presumed reasons is that current agronomic practices constraining teff productivity. By planting seed in rows at a low seed rate instead of the traditional practice of broadcasting seed at a high rate, yield is shown to improve significantly on-station. Field demonstrations of row planting of teff showed that yields increase on average by $70 \%$ compared to the national average [3]. Consequently, these new production technologies are being promoted to Ethiopian teff farmers on a large scale.

The adopter perception model suggests that the perceived attributes of innovations condition adoption behavior $[1,2]$. Thus adoption depends on users' judgment of the value of the technology to them. Users' judgment depends on many factors some personal, others reflecting on utility and efficiency of the technology. Adoption or rejection of technologies by users may reflect rational decision characteristics of the technologies under investigation. Users will reject a technology that is not relevant to their needs, not suited to their work environment and one that may interfere with other activities that are considered to be important. Their omissions in adoption model may bias the results of the factors determining adoption decision of users [2].

The rate of adoption of a new technology is subject to its profitability and the degree of risk and uncertainty associated with it and it is highly influenced by the capital requirement and agricultural policies, and the socio-economic characteristics of farmers $[17,4]$. Adoption also related and influenced with the technology profile like expenditure on hired labor and maturity period of the technology. On the other hand, factors influencing farm households adoption of modern agricultural production technologies were 
included farm size, age of farmers, cost of inputs, level of education, access to extension services and the gender implies that the factors included with the probability of farm households decisions to adopt or not modern agricultural production technologies [29].

The account for a large set of determinants relative to farmers' attitudes, expectations and socio-demographic characteristics, farm assets and constraints, informational and geographical contexts, and quantitative attributes relative to the innovations and policy generic characteristics, that have been assessed and calibrated with a preliminary study. Specific attention was given to farmers expectations and objectives that are seldom taken into account in adoption studies, and the effect on adoption is important to evaluate. Since there is no action without motivation hence the factors of motivation are strong enough to trigger adoption [29]. Adoption rates vary between different group of farmers due to the differences in access to resources as well as differences in farmers perceptions of risks and profits associated with new technology [30]. Farmers' decisions to adopt a new technology in preference to other alternative technologies depend on complex factors. Farmers have subjective preference for technology characteristics which could play major role in technology adoption.

Most of the work done on adoption behaviour focused on only independent variables. An author [12] is perhaps the only researcher who did research on the psychological aspects of technology (innovation) transfer and adoption in South Africa. He developed a "revised extension program model" which offers a big scope for improvement in extension directly influenced by a new approach towards behaviour change. In 1994 he also developed a model of technology transfer in agricultural development on the assumption that certain "intervening" variables influence adoption behaviour directly, while the influence of more independent variables only shows its effect via the intervening variables. Further he also developed a model to determine adoption behaviour and found that personal and environmental factors are the independent variables, while needs, knowledge and perception are the intervening variables and adoption of practices and efficiency are the dependent variables. Non adoption of new technologies can be traced back to unwillingness or incapability (related to aspects of perception and knowledge) to adopt [13].

Following Duvel, Habtemariam studied the influence of intervening variables on adoption behaviors and production efficiency in Ethiopia. Adoption behaviours and production efficiency were hypothesized to be a function of personal and environmental factors, which in turn are divided into independent and intervening variables identified by [16]. Empirical evidence provided by [11] on the role of perception on behavior and behavioral consequences supports the assumption that the influence of the independent variables becomes manifested in behavior via the intervening or mediating variables. Subsequent findings by [13] have reaffirmed that the mediating function of perception together with needs and knowledge.

\section{Research Methodology}

The study was conducted in West Showa Zone of Oromia region at Gindeberet district of as it has the largest tribal population. The research adopted the descriptive survey research design. Data was collected from farmers within the operational areas of the district.

Multi-stage sampling methods were used to select the respondents in this study. First Gindeberet district was selected as a study area since the area has high potential for teff production, stage two; six peasant associations (PAs) were selected from the district. The PAs identification was made through reviewing secondary data on production potential of teff and dissemination of the Quncho teff technology and area coverage of the crop and; final stage 150 farmers were selected randomly as sample respondents to analyse the perception of the farmers on Quncho teff technology using systematic random sampling technique from each PAs based on probability proportional to size. From the selected sampled respondents made up of 112 males and 38 females were randomly selected from the farmers who grow teff crops. The selected respondents were interviewed personally with the help of a well-structured and pre-tested interview schedule in order to get relevant information.

\section{Result and Discussion}

\subsection{Improved Quncho Teff Varieties Adoption in the District}

Teff in the study area is the major crop commodity for the farming households used for both consumption and income generation. This crop has attractive market price than other crop commodities like maize, sorghum, millet and others. Therefore, farmers were focused on producing teff by adopting different high yielding varieties to improve production and productivity of it. According to district office of agriculture and rural development annual report, Quncho teff variety is somehow getting attention by farmers because of its yield advantage over the other improved varieties introduced to the district. It is also white in color and has high market demand in comparison with the other teff. According to the data from the district office of agriculture, the improved teff varieties with different yield performance has been introduced so far and Quncho teff is highly productive than the other improved varieties introduced in the district.

The main crops cultivated by the respondents are teff, wheat, maize, barley millet sorghum beans, potato, root and tuber crops. These crops are cultivated on subsistence level with the surplus offered for sale to generate income. Even though some of the farmers had adopted some improved crop varieties, majority of the farmers grow the improved and the traditional varieties. However from the selected sample respondents substantial number of the farmers were still holding on to the traditional crop varieties thus these farmers had not adopted improved Quncho teff variety (Table 1). 
Table 1. Types of teff produced in the study area.

\begin{tabular}{lll}
\hline Technology used & No. of sampled respondents & Percentage \\
\hline Improved teff varieties (Quncho) & 72 & 48.0 \\
Local teff varieties & 34 & 22.7 \\
Both & 44 & 29.3 \\
Total & 150 & 100 \\
\hline
\end{tabular}

Survey: 2019, Own compilation

Farmers who grow both traditional and improved teff varieties argued that some traditional crops still have desirable traits such as good taste and ease of preservation which the improved crop varieties lack. The respondents who have not adopted any technology (improved teff varieties) were of the view that it is expensive to adopt new technologies. The farmers thus explained that using the improved crop varieties required inputs such as fertilizers and other chemicals, which they could not afford. Some of the farmers interviewed maintained that at times farmers who cultivated the improved varieties had plentiful harvest but found it difficult to market the produce. The findings confirm the investigation by [15].

\subsection{Farmer's Perception on the Technology}

Farmers' perception on use of technology is generally attached with the advantage of technology components. Farmers examine the advantages from the point view of compatibility to their current situation, with labour demand, profitability, and other social necessities to adopt a technology. If farmers perception is positive towards the advantage of technology it will enhances decision in favour of adoption of the technology [32]. According to [11] Perception is a key dimension in behavioral change process.
The more accurately a farmer perceives his current poor production efficiency, the more likely he is to alter his behavior and thereby improve his production efficiency.

Farmers perception towards improved Quncho teff variety was described and measured based on the agreement level of the respondents perceived during the data collection. Perception was measured using a scale with items developed for the purpose of this study. Based on this ground, farmers' perception of improved Quncho teff technology has been considered in this study. With regard to the assessment of perception, an index which identifies how well certain attributes of improved varieties meet farmers' preference over the local variety on five point scale was used [25]. Accordingly, the ratings such as very low (1), low (2), medium (3), high (4), and very high (5) were used to measure the respondents perception to the technologies and the larger value (5) indicates how farmer perceives the characteristics being presented for evaluation was being embodied and 4, 3, 2 , and 1 in a decreasing manner. A value less than three indicates how the farmer perceives the characteristics under evaluation as poor or negatively. The result on farmers' perception of the variety was given in Table 2 . The relative agreement was computed by dividing the mean of each variable to the total mean and multiplied by $100 \%$.

Table 2. Distribution of respondents regards their perception level on the variety.

\begin{tabular}{|c|c|c|c|c|c|c|c|c|c|}
\hline \multirow{2}{*}{ Item of agreements } & \multicolumn{7}{|c|}{ Distribution of respondents per perception category $(\%), N=150$} & \multirow{2}{*}{$\begin{array}{l}\text { Level of } \\
\text { agreement (\%) }\end{array}$} & \multirow{2}{*}{ Rank } \\
\hline & Very low & low & Medium & high & very high & mean & SD & & \\
\hline High yield potential of the variety & 14 & 20.67 & 12.67 & 30.67 & 22 & 3.26 & 1.4 & 17.80 & 1 \\
\hline Increase production and yield & 0.87 & 34.7 & 22.33 & 23.33 & 18. & 3.21 & 1.15 & 17.53 & 4 \\
\hline Perception on disease resistance & 13.33 & 34.67 & 26 & 20.67 & 5.33 & 2.8 & 1.03 & 15.29 & 5 \\
\hline Agro-ecological suitability & 0.67 & 36.67 & 21.33 & 24.3 & 18.2 & 3.24 & 1.14 & 17.69 & 2 \\
\hline Availability of seed at the right time and quality & 19.3 & 29.33 & 20.67 & 23.33 & 7.33 & 2.7 & 1.23 & 14.74 & 6 \\
\hline Sum of mean & & & & & & 18.31 & & 100 & \\
\hline
\end{tabular}

Survey: 2019, Own compilation

The survey result shown in Table 2, the technology was supported by sampled respondents for certain level of agreements such as high yield potential, increase production and yield, capability on disease resistance, availability of the technology on production, agro-ecological suitability, and availability of the improved seed at the right time with its quality.

The result showed that from the given items of agreements, a grand mean of 3.1 indicates that the overall perception on level of agreement on the varieties were showed relatively best performance whereas below the grand mean result showed, farmers perception on the variety indicates relatively poorest agreement compared to all other characteristics of level of agreements considered. Depending on the items developed for this study among the given agreements perception on disease resistance and availability of the improved seed at the right time with its quality result indicates the least scores of 2.8 , and 2.7 respectively. Low ratings on disease resistance of the variety could be due to poor management of plots, seed quality; lack of on time agronomical practices like plant protection, fertilizer application, herbicide and other. According to the sampled farmers in selected PAs of the study area, the low ratings on availability of seed at the right time and with right quality was observed the least scores due to high seed purchase 
price in the district.

Hereafter, from the finding it can be concluded that the improved variety of Quncho teff was perceived to be suitable with references of the characteristics which are perceived highly important by farmers based on the overall perception on level of agreements showed relatively best performance in the study area. According to them, farmers are considered to have subjective preference for specific characteristics inherent in new technologies and hence need to be given due concern by researchers.

\subsection{Constraints Faced Farmers in Producing Improved Teff Variety}

More than $80 \%$ of the respondents reported that, inadequate and untimely supply of inputs particularly for subsidized insecticides and fungicides was the first important limitation for adoption of improved variety in general and Quncho teff variety in particular in the study area. This was due to the reason that, it leads to untimely and insufficient application of herbicides. While inadequate extension services and unavailability of improved seed at the right time at PAs level were the second important constraints. This situation discouraged farmers to participate on improved teff variety farming and also adoption of improved technologies. Other constraints for adoption of agricultural technologies by farmers include inadequate capital to participate on improved Quncho teff production, poor market integration which also discouraged farmers to adopt improved technologies, high prices of inputs particularly improved seeds, pesticides, fertilizers, insect pests, and also shortage of land were among the major problems in the study district.

\section{Conclusion and Recommendation}

It is important that for any new technology to be introduced to the farmers, farmers should be involved in its evaluation to find its suitability to the farmers' circumstances. The analyses in this paper showed those farmers' subjective preferences for characteristics of new agricultural technologies are very important determinants of adoption behavior. Substantial efforts have been made by research center and district office of agriculture and other nongovernmental organizations to develop improved Quncho teff varieties in the study area, but also dissemination of these technologies in collaboration with other stakeholders was relatively low. Several factors are mentioned as being responsible for this hindrance. These include unavailability of improved seed at PAs level, inadequate and untimely supply of inputs, shortage of land, inadequate extension services as well as inefficient marketing system.

Grounding on this finding, the following recommendations were made: Inputs should be supplied to farmers timely and at affordable prices since improved teff variety production can improve the livelihood of the farmers if inputs are used. Extension services should be improved in order to build the capacity of farmers on agricultural technology production in general and improved quncho teff in particular. The government and other stakeholders should invest in farmer training since it enables farmers to understand well technologies and perceive their benefits increasing their probability to adopt it as it was shown in the study that farmers who had received some formal training in agricultural. In future research, it is recommended that more improved seed introduced to farmers in a particular area be examined using the same criteria used in this study, in which case they can be ranked in terms of suitability using both conjoint results and farmer scoring of the improved variety in the particular attributes.

\section{Acknowledgements}

The authors wish to express special thanks to the farmers, agricultural development agents, and local administrators of the study area for their assistance during the field work by providing necessary data and information in the whole research process. Our special thanks also go to anonymous reviewers and editors of the journal for their efficient and effective management of the review and publication process of the manuscript.

\section{References}

[1] Adesina, A. A. and M. M. Zinnah. 1993. Farmer Perceptions and Adoption Decisions: A Tobit Model Application in Sierra Leone. Agricultural Economics, 9: 297-311.

[2] Adesina, A. A., \& Baidu-Forson, J. (1995). Farmers' perceptions and adoption of new agricultural technology: Evidence from analysis in Burkina Faso and Guinea, West Africa. Agricultural Economics, 13, 1-9.

[3] ATA, 2013. "Results of 2012 New Teff Technologies Demonstration Trials Draft Report VF". Addis Ababa, Ethiopia.

[4] Akudugu et al, 2012 Adoption of modern agricultural production technologies by farm households in Ghana: What factors influence their decisions Journal of Biology, Agriculture and Healthcare www.iiste.org ISSN 2224-3208 (Paper) ISSN 2225-093X (Online) Vo 1 2, No. 3, 2012.

[5] Asrat Wondimu and Frew Tekabe, 2001. Utilization of teff in the Ethiopian diet: 239-244. In: Hailu Tefera, Getachew Belay and Mark Sorrels (eds.) Narrowing the Rift: Teff Research and Development, Proceedings of the International Workshop on teff Genetics and Improvement, 16-19 October 2000, Addis Ababa, Ethiopia.

[6] Bezabih Emana. And Hadera G/medhin. 2007. "Constraints and Opportunities of Horticulture Production and Marketing in Eastern Ethiopia”. DCG Report No. 46.

[7] CSA (Central Statistical Authority). 2009 Agricultural sample survey 2008/2009 E.C. Report on area and production for major crops (private peasant holdings). Statistical bulletin Addis Ababa, Ethiopia.

[8] CSA. 2015. Central Statistical Agency, Statistical Bulletin 578 Addis Ababa, Ethiopia. Darst BC and PE Fixen. 2000. High yields, high profits, and high soil fertility. Better Crops 84 (1): $1-8$. 
[9] CSA, 2013. "Agricultural Sample Survey: Area and Production of Major Crops, Meher Season". Vol. I. Addis Ababa, Ethiopia.

[10] Dekking, L. S, and Koning, K. F. 2005. The Ethiopian Cereal Teff in Celiac Disease. The New England Journal of Medicine. 353: 16

[11] Duvel, G. H. (1975). The Mediating Functions of Perception in Innovation Decision. South African Journal of Agricultural Extension, 4, Pp. 25-36.

[12] Düvel, G. H., 1991. Towards a model for the promotion of complex innovation through programmed extension, S. Afr. J. of Extension. 20: 70-86.

[13] Düvel, G. H., 1994. Coping with Felt and unfelt Needs in Programmed Extension. S. Afr. J. of Extension: 28-34.

[14] Evert, S., Staggenborg, S. and Olson, L. S. 2009. Soil temperature and planting effects on teff emergence. Journal of agronomy and crop science. 195: 232-234.

[15] Emmanuel Asiedu - Darko. Farmers' Perception on Agricultural Technologies a Case of Some Improved Crop Varieties in Ghana. Agriculture, Forestry and Fisheries. Vol. 3, No. 1, 2014, pp. 13-16. doi: 10.11648/j.aff.20140301.13.

[16] Habtemariam Abate, 2004. The comparative influence of intervening variable in the adoption of maize and dairy farmers in Shashemene and Debrezieit, Ethiopia. PhD Thesis, University of Pretoria.

[17] Jariko et al; 2011; Socioeconomic Factors Affecting Adoption of Sunflower Varieties in Sindh, 2011 Vol. 5 (1), 192-201.

[18] Kebebew et al; 2017. Tef, Eragrostis tef (Zucc.) Trotter. In: Patil JV (ed) Millets and Sorghum: Biological and Genetic Improvement). WileyBlackWell Publisher.

[19] Legese Dady, 2004. Agricultural Research and Technology Development in Ethiopia. Proceedings of the workshop held to discuss the socio-economic research results of 1998-2002. August 6-8, 2002, Addis Ababa, Ethiopia. EARO, 2004.

[20] Mizan et al;. 2017. Achievements and gaps in tef productivity improvement practices in the marginal areas of Northern Ethiopia: implication for future research directions. International Journal of Agricultural Sustainability 15 (1): 4253.

[21] MoANR. 2017. Ministry of Agriculture and Natural Resources, Plant Variety Release, Protection and Seed Quality Control Directorate, Crop Variety Register, Issue No. 20, June 2017, Addis Ababa, Ethiopia.
[22] MoARD (Ministry of Agriculture and Rural Development), 2008. Crop variety register, Animal and Plant Health Regulatory Directorate, Addis Ababa, Ethiopia, June 2008.

[23] Provost C and E Jobson. 2014. Move over quinoa, Ethiopia's teff poised to be next big super grain. The Guardian, January 23, 2014.

[24] Rashid, S. and Assefa, M. 2006. Sources, extents and policies to manage food price risks in Ethiopia: How does it fare with other developing countries? Paper presented at the "Ethiopian Strategy Support Program 2006 Policy Conference," June 6-8, 2006, Addis Ababa, Ethiopia.

[25] Rahmeto Negash, 2007; Determinants Of Adoption Of Improved Haricot Bean Production Package In Alaba Special Woreda, Southern Ethiopia. M. Sc. Thesis; October, 2007 Haramaya University.

[26] Spaenij-Dekking L, Y Kooy-Winkelaar, F Koning. 2005. The Ethiopian cereal tef in celiac disease. New England Journal of Medicine 353: 1748-1749.

[27] Spielman et al 2008, an innovation systems perspective on strengthening agricultural education and training in subSaharan Africa.

[28] Tareke Berhe and Nigusse Zena, 2008. Results in a trial of system of teff intensification (sti) at Debre Zeit, Ethiopia.

[29] Tshiunza, M., Lemchi, J. and Tenkouano, A. 2001. Determinants of market production of cooking banana in Nigeria. Africa Crop Science Journal. 9 (3): 537-547.

[30] Tesfaye et al; 2001. Adoption of improved bread wheat varieties and inorganic fertilizer by small-scale farmers in Yelmana Densa and Farta Districts of Northwestern Ethiopia. Mexico, D. F.: CIMMYT and Ethiopian Agricultural Research Organisation (EARO).

[31] Tsibuk Berhe, 2015, Factors Affecting Adoption Of Quncho Teff Variety: The Case Of Medebayzana Woreda, NorthWestern Administrative Zone Of Tigray Region, Ethiopia, January 2015 Haramaya University.

[32] Tadesse Adgo Mihiretu 2008, Farmers' Evaluation And Adoption Of Improved Onion Production Package In Fogera District, South Gondar, Ethiopia: M. Sc. Thesis June 2008 Haramaya University.

[33] USAID, 2012. Improved Grain Varieties: Impact through Research and Development, tool for transformation, capacity to improve agriculture and food security. 13: 1.

[34] World Bank, 2006. Africa Development indicators 2006. Washington DC. 